\title{
Complejidades del feminismo
}

\section{Mariflor Aguilar}

\author{
Anne Phillips, Género y teoría democrática. \\ México, unam, Programa Universitario de Estudios \\ de Género, Instituto de Investigaciones Sociales, 1996.
}

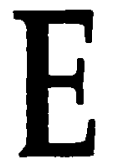

n este libro Anne Phillips analiza diversas acciones y posiciones reivindicativas del feminismo mostrando su complejidad y observán. dolas desde múltiples aspectos sin adherirse a ninguno acríticamente y sin dar por sentado que deben aceptarse in toto. Suele ocurrir en este texto que aquello a lo que dedica páginas enteras de elogio y defensa es también a lo que dedica más observaciones críticas o problemáti. cas. Esto sólo me parece ya un gran mérito de la autora y que hace valioso al libro.

El libro recoge multitud de datos sobre los movimientos feministas en varios paises y su relación con sus respectivas democracias, sobre todo con relación al tema de la participación política de las mujeres. Lo que muestran estos datos es que aunque la situación del movimiento es específica en cada caso, en general hay avances en la participación de las mujeres aun cuando no haya sido ni esté siendo fácil alcanzar las metas propuestas.

Algunos de los temas concretos que se tocan son los siguientes:

Hace una revisión del lugar de las mujeres en los debates clásicos sobre la democracia y muestra que en la teoria política, habitualmente de naturaleza abstracta, no hay lugar ni para la vida cotidiana ni para los accidentes de género y clase (p. 16). Sin embargo, intenta mostrar que donde especialmente no hay cabida para tales espacios no es en toda teoria política sino en especial en aquélla que detenta una concepción representativa de la democracia, lo que no ocurre de la misma manera en la que tiene una visión participativa de la misma.

Sin embargo, apunta también problemas varios en relación con este punto. Se refiere a las dificultades que entraña la participación de las mujeres debido precisamente a la falta de igualdad que establecen las relaciones laborales, a las formas específicas de agrupación femenina o a las dificultades planteadas simplemente por la desigualdad de preparación para participar, 
establecida por la cultura patriarcal. Destaca los obstáculos que representa lo que habitualmente se conoce como la doble jornada de trabajo, perspectiva desde la cual no hay tiempo que alcance para la realización de actividades políticas al mismo tiempo que para el cumplimiento de compromisos básicos de la vida cotidiana como las tareas relacionadas con los hijos, la casa, el cuidado de ancianos o enfermos, etcétera, que de manera natural contraemos las mujeres, puesto que la noción masculina del trabajo no contempla estas actividades entre sus responsabilidades mínimas.

Se refiere también a la forma de participación de los pequeños grupos de mujeres; reconoce la importancia que ha tenido tal experimento, la enseñanza vital para cada una de las participantes, pero también señala algunos de sus problemas, tales como miedos e inseguridades ante líderes o ante mujeres más y mejor preparadas o que toman la palabra con más frecuencia o más seguridad personal.

Trata también la cuestión de las cuotas de representación de las mujeres. Aunque inicialmente considera que la defensa de los "intereses" de mujeres no significa una defensa localista o provincialista, puesto que las mujeres somos más de la mitad de la población, problematiza también el programa de las cuotas señalando que no todas las mujeres necesariamente defienden intereses femeninos. Explica que puede ocurrir que un representante hombre que quiere más guarderías o un salario mínimo más alto (p. 75) sea mejor para las mujeres que una mujer que no se identifica con el feminismo ni con sus luchas. Señala también que no existen "las mujeres" sino "mujeres realmente existentes" que no comparten opresiones idénticas; y también se refiere a las divisiones profundas que puede haber entre nosotras (p. 78). Esta es una discusión que permanece abierta y el mérito de Phillips es haber distinguido diferentes ángulos para la discusión y argumentación.

Aunque la cuestión de las cuotas es un tema que importa, Anne Phillips pasa a analizar asuntos relacionados más con la participación que con la representación, para lo cual se refiere a la articulación compleja entre "la política", "lo político", lo público y lo privado y la bandera "lo personal es político". Inicialmente cuestiona la definición circular de "lo público" y "lo político" que en general se refieren a las actividades desarrolladas en las cámaras, en el lugar de toma de decisiones de las secretarías de Estado o en sus equivalentes más pequeños. En suma, lo político tiene que ver con decisiones públicas y ocurre en espacios públicos. Lo "público" es donde actúa la política. Así, a lo privado no se le incluye en lo político. De estas acepciones limitantes se levanta la bandera "lo personal es político".

A Phillips no le cabe ninguna duda de que "lo personal es político" es un lema fundamental en los movimientos de mujeres. Las reivindicaciones feministas por la igualdad en la esfera privada son tan políticas como la lucha por 
aspectos más generales sobre los que se debate desde los partidos o las cámaras. Es un lema que ha significado que en toda estructura de opresión y explotación debe librarse una lucha (p. 95). Ha significado que la igualdad política entre hombres y mujeres debe incluir cambios sustanciales en la esfera doméstica. Es un lema que ayudó

[...] a que las mujeres vean que lo que creían que les era peculiar (personal, exclusivo y tal vez básicamente su culpa) puede que sea parte de un modelo general de relaciones sexuales que está abierto al cambio político. Por otra parte, da a las mujeres la confianza en sí mismas para reivindicar el tipo de cambios que ya pueden hacer (negarse a hacer la comida o a mecanografiar el documento [...] del hombre) como políticamente importantes. La política se convierte entonces en [...] lo que hacemos en nuestra vida cotidiana" (p. 112).

Esta gran enseñanza que sin duda ha aportado el feminismo no impide a la autora exponer también la crítica al lema, crítica que en general no niega la articulación de lo personal y lo político pero que a su vez se niega a establecer una identidad entre ambos polos. Phillips cita a Carole Patema, quien observa que no se puede afirmar "que nuestras interacciones y tomas de decisiones como ciudadanos deberian ser ordenadas exactamente por los mismos criterios y principios que los que deberían estar en el fondo de nuestras relaciones con amigos y amantes" (p. 105).

Esta es la posición que va a sostener la autora en relación con la separación entre lo público y lo privado. Claramente se defiende una política que incluya los temas de la vida cotidiana que las mujeres suelen vivir con más intensidad y de manera más conflictiva, pero esto no significa para la autora que se deba abandonar la distinción entre lo público y lo privado o entre lo personal y lo político. Que lo personal sea político puede significar por un lado que el Estado o la sociedad tienen derecho a inmiscuirse en todos los asuntos de nuestra vida privada; por otro lado puede implicar que delegamos a otros la responsabilidad de todos nuestros asuntos (p. 107). Esto sería incompatible con lo que quieren la mayoría de las mujeres.

Hay espacios en los que, en efecto, el Estado podría intervenir para facilitar la igualdad en la vida privada, como por ejemplo, revisar los horarios de las jornadas de trabajo de los hombres, facilitar guarderías, igualación de salarios, etcétera; más aun así hay otros asuntos que queremos decidir individualmente. También el tema del aborto suele defenderse argumentando la diferencia entre lo público y lo privado y reconociendo "al individuo como autónomo en la esfera privada" (p. 107). "Ninguna intervención social puede dictar lo que sucede entre amantes o entre maridos y esposas, y con la 
excepción del daño corporal, la mayoría de las personas prefiere que sea así", dice Phillips (p. 112).

Al final, lo que sostiene la autora es que "lo personal es político" no debería borrar la frontera entre lo público y lo privado sino más bien pensar que hay espacios en que el Estado no debe intervenir, pero que al mismo tiempo son las mujeres las que tienen que cambiar la agenda pública para incluir en ella prácticas consideradas "triviales" como para discutirlas públicamente (p. 115).

Seguramente de esta defensa de la distinción entre lo público y lo privado Phillips puede pasar fácilmente a la defensa de la distinción entre lo general y lo particular y entre lo universal y lo particular. Intenta establecer un puente entre ambos polos de los dos pares en lugar de disolver uno en el otro o de disociarlos irremediablemente.

Señala que desde los movimientos sociales, especialmente desde el movimiento de las mujeres, se plantea la desconfianza del universalismo ilustrado en tanto que excluye la experiencia sexualmente diferenciada. Anne Phillips está de acuerdo con esta desconfianza pero al mismo tiempo considera que no hay que anular del todo la universalidad y conservar solamente "una teoria inmoderada de la diferencia" como ella le llama (p. 64).

Su interés en conservar aspectos de la universalidad está basado en que considera que reflexionar solamente en términos de las diferencias puede implicar riesgos diversos como los siguientes:

10. El de promover un obstáculo, en cierta medida antidemocrático, para la identificación y solidaridad con otros grupos. El pensamiento extremo de las diferencias puede bloquear la conciencia de los derechos iguales asi como la conciencia de los rasgos comunes.

20. Al tener una noción diferencialista radical de los seres humanos se pone en juego también la posibilidad de pensar en ideales más generales en los que se involucre a grupos diversos pensados en otros términos, bien en términos de seres humanos (como en el caso de los derechos) o en términos de "ciudadanos". Dice la autora: "El hecho de que la gente encuentre más fácil identificarse con lo que le es más cercano no establece de modo concluyente la falta de pertinencia de cualquier ideal más grandioso'." (p. 62).

30. El tercer riesgo del diferencialismo radical es el de posicionarse en el polo opuesto al universalismo, que significaria situarse en algún esencialismo,

I Aclaro que la formulación de esta cita no me parece adecuada. Tal parece que los ideales estrictamente de género, por diferenciales no pueden aspirar a ser grandiosos. El planteamiento correcto debería ser cualquicr ideal "más universal" o "más general", p. 62 . 
es decir, considerar que cada persona está definida únicamente por un aspecto, en este caso el de género.

Una muestra de esto es el luminoso texto de Luz Aurora Pimentel "Y tú, ¿quién eres?" aparecido en Debate feminista. En este artículo L. A. Pimentel muestra que la identificación con el género en algunas circunstancias no es suficiente para expresar lo que se es. Imagina que los formularios administrativos puedan ayudar a pensar la identidad al poner una $X$ en el casillero correspondiente: nombre, apellido, estado civil, sexo, etcétera. En relación con los casilleros de "sexo" dice:

No quepo en los barrotes de la " $F$ ", nunca he cabido [...] Ha habido épocas en las que ni a sexo llego [...] Pero lo que sí sé es que desde siempre, al despertar no soy más que un haz de sensaciones, una conciencia reticulada que palpita en púrpura detrás de los párpados soñolientos [...] Mas el ser y la conciencia también tienen infinidad de pliegues [...] y esos recovecos. hacen de todos los años una simultaneidad que se siente en la piel [...] Sobre todo cuando estoy enamorada; me duermo y me despierto con la imagen del amado arañándome las entrañas, la garganta y el sexo - en ese (des)orden- [...] y el alma se me ilumina, como si después de haber "hilvanado los oscuros ojos de la noche" hubiera llegado a un claro del bosque al amanecer. $^{2}$

Luego imagina que en ese momento llegara un reportero de la revista -conocida- a preguntarle:

"y tú, ¿quién eres?", me echaria a llorar -dice- y le diría que soy enamorada, que no puedo pensar en otra cosa y que, por lo tanto ¿no puedo ser otra cosa? Pero luego también me da por ser madre y no puedo pensar en otra cosa [...] ¿Qué seré? ¿Todo? ¿Nada? Lo que sí, clavada y de seguro, es que soy monomaniaca apasionada, y todas mis monomanías [...] ya sea en sucesión, alternancia o superposición, desde luego no caben en la susodicha " $F$ ", aunque le torciera los barrotes y les hiciera una extensión. ${ }^{3}$

Este tema de la complejidad de la identidad que impide las identificaciones simples lo esboza también Anne Phillips: no hay esencia del yo detrás de nuestras diferencias, pero tampoco hay "una diferencia que esencialmente

\footnotetext{
${ }^{2}$ Luz Aurora Pimentel, "Y tú, ¿quién eres?", en Debate Feminista, núm. 14, p. 150.

${ }^{3}$ Ibid., p. 151.
} 
constituya nuestro yo. Los rasgos esenciales van cambiando" (p. 64). Dice Anne Phillips: "la mayoría de la gente existe en múltiples identidades, cada una de las cuales puede llegar a ser la dominante durante un tiempo" (p. 152).

En suma, lo que queda sugerido es que ni lo universal ni lo particular solos son suficientes como clave explicativa o referencial en la teoría feminista.

Me parece que la lectura de este libro deja clara la vastedad de la participación política de las mujeres; aclara que no tenemos que alejarnos de nuestra posicionalidad femenina para participar en asuntos políticos que no tienen a la mujer como punto de referencia; muestra también la complejidad de casi todos los temas relacionados con el movimiento feminista incluso el significado mismo de "ser mujer"; pero esto, más que descorazonar se percibe como el resultado de un proceso de maduración del movimiento y una ampliación de la reflexión. 